\title{
25 Research Soure \\ Validating A Smartphone-Based Biomarker Tool Lyfas in Screening Anxiety Disorders
}

Subhagata Chattopadhyay ( $\square$ subhagata.chattopadhyay2017@gmail.com )

Acculi Labs Pvt. Ltd

Rupam Das

Acculi Labs Pvt. Ltd

Shalini Gaur

Acculi Labs Pvt. Ltd

\section{Research Article}

Keywords: Anxiety, Lyfas anxiety score, statistical validation, Hamilton anxiety rating scale, Bland-Altman reliability test, Correlation, ANOVA, Linear regressions, Two-sample t-test, SD1/SD2, vaccines, vaccination

Posted Date: January 3rd, 2022

DOl: https://doi.org/10.21203/rs.3.rs-1169947/v1

License: @ (i) This work is licensed under a Creative Commons Attribution 4.0 International License. Read Full License 


\section{Abstract}

Lyfas is a smartphone-based biomedical application that captures the cardiovascular autonomic biomarkers $(\mathrm{CVb})$, surrogating for mental health attributes. SD1/SD2 biomarker assesses the sympathovagal balance and is considered to be a potential indicator of Lyfas anxiety score (LAS). A total of 1837 males and 973 females took Lyfas (hypersensitivity-checked) and Hamilton Anxiety Rating Scale (HAM-A) self-scoring tests. LAS has been statistically validated by Linear regressions, one-way ANOVA, t-stat, correlations ( $r$ ), and Bland Altman agreement assessment with respect to HAM-A. Sensitivity, specificity, precision, accuracy, Fscore, and Youden's index (j-stat) are computed. Results show that (i) Lyfas is not a very hypersensitive instrument (mean-variance is 0.6 ). (ii) It can predict HAM-A with $94.7 \%$ accuracy $\left(R^{2}\right)$ and is a statistically significant model $(p<0.05)$. (iii) LAS and HAM-A are positively correlated by $97 \%$, the t-stat value of 5.38 for the population indicates that the two instruments have a significant mean difference. (iv) Bland Altman test showcases the overall agreement of $12.95 \%$ due to different modes and scales of measurements. (v) on average, LAS is $87.78 \%$ accurate, $86.82 \%$ precise, and its' $65.2 \%$ j-stat value proves that Lyfas is a novel industry-standard smartphone biomarker application that can be used to accurately screen anxiety disorders.

\section{Introduction}

Anxiety disorder is the most common mental health issue according to the American Psychiatric Association, affecting nearly $30 \%$ of adults [1]. Imbalance in the hippocampus, amygdala and cingulate gyrus, and prefrontal cortex leads to the hyperactivation of (i) hypothalamus-pituitary-adrenal cortex axis and (ii) autonomic nervous system, and adrenal medulla [2]. As a result, a higher amount of cortisol and epinephrine are released in the blood, which causes a maladaptive emotional state in the form of worries, apprehensions, and related tension [2]. Often, a strong familial history is also present in generalized anxiety disorders [3]. Its high prevalence rate is evident in the ongoing COVID-19 pandemic period [4], affecting mostly middle-aged and senior citizens [5]. The precipitating factors are mostly around the queries on the (i) newer variants of the virus and its damaging potential, (ii) administrative policies such as lockdowns and travel restrictions to break the transmission chain, (iii) potency of the vaccine against new strains and side effects of the vaccines, and (iv) dealing with the comorbid conditions, which potentially affects the innate immunity. Anxiety itself is contagious which leads to an accumulation of anxious minds in society [6]. There are online anxiety screening and counseling platforms for one-to-one discussion of these mental problems [7] [8]. However, most are oneway traffic of advice from the counselors, the validation of which is not known to the best of the knowledge of the authors. The need for scientific validation is because anxiety disorders present with different sets of signs and symptoms in different individuals and the interpretation of these signs and symptoms also vary among the counselors. Online apps are developed by computer scientists who have no domain knowledge. Nonetheless, the domain experts' views on developing the questionnaire and its interpretation need solid validation to a well-acclaimed anxiety screening tool/instrument. Hence, undeniably there lies a chance of errors in the decision-making and management plan.

Mobile health (mHealth) is a pervasive way of catering health to a larger population due to an increasing number of smartphone users, availability of low-cost mobile data, and a wider internet network. By virtue of the built-in optical sensor and the LED light in the smartphone camera, it captures the Pulse rate variability (PRV) from the index finger capillary using the principle of photo reflectant Arterial photoplethysmography 
(APPG), when the finger is pressed on the main rear camera of the phone [9]. Filtered PRV signals surrogate for the Cardiovascular autonomic modulation (CvAM), which can be assessed by measuring the short Heart rate variability (2 min HRV) and its correlated Cardiovascular biomarkers (CVb) [10]. Studies found that HRV scores are influenced by the mental health state, and anxiety disorders lower the HRV scores [11]. Lyfas is such a commercially available biomedical application [12].

Any novel instrument, which is proposed as a potential tool in the healthcare domain, mandates its reliability/validity check. In this work, the validity of Lyfas anxiety score (LAS) is checked statistically as a pervasive 'anxiety screening tool' on a well-acclaimed tool called 'Hamilton anxiety rating scale (HAM-A)' selfscore.

\section{Methods}

Ethical clearance. Ethical committee clearance has been obtained for this study from Vagus Institutional Ethics Committee (EC Registration Number: ECR/1181/Inst/K.A., 2019, Date of clinical trial registration: 30/01/2020). Informed consent of all participants was obtained as per the Helsinki declaration (1989) before the trial with Lyfas and at the start of the test based on the verbal prompt of the application.

Recruitment of the subject. A total of 1837 males and 973 females within the age group of 51-100 years (51$60,61-70,71-80,81-100$ years) were recruited for a double-blind control trial from August 2021 to November 2021 in Karnataka India. HAM-A had been undertaken by the participants based on the self-scoring technique. Simultaneously they also took Lyfas tests for three consecutive days to capture the values of LF/HF and SD1/SD2 as LAS.

HAM-A scale. It is a well-recognized 'clinical rating scale' for the 'psychic' as well as 'somatic' anxiety for all age groups having 14 questions or items (see Table 1 ), each is rated using a 5 -point-scale ( 0 to 4 , where ' 0 ' refers to 'absent', and ' 4 ' refers to 'severe'). HAM-A self-scoring has been performed age-group (51-60, 61-70, 71-80, 81-100 years respectively) and gender-wise.

Table 1

Items/questions (1-14) and interpretation by HAM-A rating scale

\begin{tabular}{|lllll|}
\hline $\begin{array}{l}\text { 1. Anxious } \\
\text { mood }\end{array}$ & 2. Tension & 3. Fears & 4. Insomnia & 5. Intellectual \\
\hline $\begin{array}{l}\text { 6. Depressed } \\
\text { mood }\end{array}$ & $\begin{array}{l}\text { 7. Somatic } \\
\text { (muscular) }\end{array}$ & $\begin{array}{l}\text { 8. Somatic } \\
\text { (sensory) }\end{array}$ & $\begin{array}{l}\text { 9. } \\
\text { Cardiovascular } \\
\text { symptoms }\end{array}$ & 10. Respiratory symptoms \\
$\begin{array}{l}\text { 11. } \\
\begin{array}{l}\text { Gastrointestinal } \\
\text { symptoms }\end{array}\end{array}$ & $\begin{array}{l}\text { Genitourinary } \\
\text { symptoms }\end{array}$ & $\begin{array}{l}\text { 13. } \\
\text { Autonomic } \\
\text { symptoms }\end{array}$ & $\begin{array}{l}\text { 14. Behavior at } \\
\text { interview }\end{array}$ & $\begin{array}{l}\text { Range of total score: } 0 \text {-56. Mild: }<17 ; \\
\text { Mild to moderate: } 18-24 ; \text { Moderate to } \\
\text { severe: 25-30; and Severe: }>30 .\end{array}$ \\
\hline
\end{tabular}

LAS. Lyfas is a commercially available smartphone-based pervasive biomedical application that provides a visual snapshot of mind-body homeostasis by assessing the optical biomarkers using its proprietary algorithm (see Table 2) [13]. Recently, Lyfas has detected subclinical depression in a set of 86 adults and its cascading effects, such as negative thoughts and insomnia with appreciable accuracy [14]. Anxiety leads to sympathetic overdrive, reflected in the PRV (synonymous with HRV) and the SD1/SD2 scores are the key 
optical biomarkers that measure the extent of sympathovagal balance, where a higher value of the ratio points towards sympathetic dominance [15]. SD1 measures the diastolic blood pressure, the difference between the maximum and minimum HR, RMSSD, pNN50, SDNN, the power in the LF and HF bands, and total power during a short-term recording [16]. On the other hand, SD2 measures short and long-term HRV in ms and correlates it with the LF power and Baroreflex sensitivity [16]. Baroreflex prompts shared responses of the autonomic nervous system that means when the afferent Baroreflex traffic increases that raises blood pressure, the efferent traffic sympathetic traffic decreases, and the efferent parasympathetic traffic increases [17]. The ratio, therefore, measures the changeableness of the R-R time series and hence the sympathovagal balance during the stage of sympathetic activation [18]. LAS obtained is the average of three readings of SD1/SD2 taken at 7 am, $2 \mathrm{pm}$, and $10 \mathrm{pm}$ to examine if there is any inherent hypersensitivity in the readings (i.e., data capturing by the algorithm). Hypersensitivity is not desired for any healthcare instrument as it may give an error at times [19]. Similar to HAM-A, LAS has been taken according to age group and gender. Fig. 1 shows the hypersensitivity score of Lyfas if any. LAS and HAM-A line plots, age, and gender-wise, can be seen in Fig. 2.

Table 2

LAS and grades based on the average readings at $7 \mathrm{am}, 2 \mathrm{pm}$, and $10 \mathrm{pm}$

\section{Non-linear}

SD1 (range: 10 - 12)

SD2 (range: 86 - 89)

SD1/SD2-based LAS:

Range of total score: $0-40$. Mild: $>2.5$ - 10; Mooderate: >10-20; Severe: $>20-30$; and Very severe: $>30$ - 40 .

Statistical analysis. The LAS and HAM-A self scores when compared to their respective mean scores, gender, and age-wise provide the snapshots of their respective distributions in the sample population. Fig. 2 shows the distribution patterns. LAS has been validated on HAM-A self-score by performing (i) Linear regressions and one-way ANOVA (Fig. 3), (ii) Two-sample t-test (t) (its results can be found in Table 3), and iii) Bland-Altman reliability (BAR) tests, age and gender-wise can be noted in Fig. 4. Linear regressions showcase the percent data fit of LAS on the HAM-A self-score. ANOVA has been conducted to see whether there is any difference in the mean within the class or interclass data. The two-sample t-test is to compare the differences between the mean scores of LAS vs. HAM-A scores, and Bland Altman plots are for examining the mean score differences between LAS and HAM-A self-score by constructing a limit of agreement. Finally, a classification mapping has been performed between L anxiety scores on HAM-A self-score, and sensitivity, specificity, precision, accuracy, Fscore, and Youden's index are calculated (see Table 4).

\section{Results And Discussions}

In this section, experimental results are shown and discussed.

Lyfas hypersensitivity test. Testing the robustness of any instrument is mandatory to assess its efficacy and in any medical instrument, it is the most important step. Below, Fig. 1 shows the values of LAS (SD1/SD2) for males and females. For males in 51-60 years, the variance is $0.4,0.0,0.4$ at $7 \mathrm{am}, 2 \mathrm{pm}$, and $10 \mathrm{pm}$ readings with the range of 0.41-37.89 (mean 2.67 \pm 3.021 ). For $61-70$ years, the variance is $0.2,0.0,0.2$ at $7 \mathrm{am}, 2 \mathrm{pm}$, 
and $10 \mathrm{pm}$ readings with the range of $0.14-29.08$ (mean $2.86 \pm 2.89$ ). In the case of 71-80 years, the variance is $0.27,0.1,0.3$ at $7 \mathrm{am}, 2 \mathrm{pm}$, and $10 \mathrm{pm}$ readings with the range of $0.26-30.53$ (mean $3.71 \pm 4.62$ ). Finally, in the age group of $81-100$ years, the variance is $0.17,0.23,0.07$ at $7 \mathrm{am}, 2 \mathrm{pm}$, and $10 \mathrm{pm}$ readings with the range of 0.46-11.61 (mean $2.2 \pm 2.01$ ). For females in 51-60 years, the variance is 0.0, 0.4, 0.4 at 7 am, $2 \mathrm{pm}$, and $10 \mathrm{pm}$ readings with the range of $0.51-41.63$ (mean $2.72 \pm 2.99$ ). For 61-70 years, the variance is 0.23 , $0.37,0.13$ at $7 \mathrm{am}, 2 \mathrm{pm}$, and $10 \mathrm{pm}$ readings with the range of $0.25-21.84$ (mean $3.45 \pm 3.65$ ). In the case of $71-80$ years, the variance is $0.03,0.37,0.33$ at $7 \mathrm{am}, 2 \mathrm{pm}$, and $10 \mathrm{pm}$ readings with the range of 0.71-35.4 (mean $3.51 \pm 5.36$ ). Finally, in the age group of $81-100$ years, the variance is $0.37,0.04,0.33$ at 7 am, $2 \mathrm{pm}$, and $10 \mathrm{pm}$ readings with the range of 0.81-12.72 (mean $3.1 \pm 3.25$ ). According to the hypothesized LAS grade, the mean score of each age group in the population is showing 'mild' LAS, which indicates the fact that the average of the chosen population has anxiety disorders, and therefore, it is evident that there is not much deviation among the LAS in a day when captured at three different timestamps. Should Lyfas be hypersensitive, the deviations would be random and much bigger than (e.g., mild vs moderate, or moderate vs severe, or normal vs. moderate, normal vs severe, and so forth) what has been found in this study. Based on the above observation (average variance of 0.6 for the population), it can be ascertained that Lyfas is a robust mobile healthcare application.

HAM-A and LAS distributions compared to their average values. The distribution of LAS and HAM-A scores are as follows:

\section{A. In males:}

(i) 51-60 years $(\mathrm{N}=977)$ that have (a) LAS and HAM-A score less than their respective average scores of 2.67 and 1.64 are $74 \%$ and $78.3 \%$ respectively, which reflects the fact that the level of anxiety within this group is closely matching. Similar pictures can be found in the remaining grades, e.g., in (b) Mild Anxiety with LAS: >2.5-10 and HAM-A score: $<17$ is $25.8 \%$ each, (c) Moderate Anxiety with LAS: $>10-20$ and HAM-A score: 18-24 is $1.8 \%$ each, (d) Severe Anxiety with LAS: $>20-30$ and HAM-A score $25-30$ is $0.4 \%$ each, and (e) Very Severe Anxiety with LAS: $>30$ and HAM-A score:>30 is $0.2 \%$ each. Similar patterns could be seen in other age groups, as described below.

(ii) 61-70 years $(\mathrm{N}=633)$ that have: (a) LAS and HAM-A score less than their respective average score of 2.86 and 2.77 are $72.2 \%$ and $67.8 \%$, (b) Mild Anxiety with LAS: $>2.5-10$ and HAM-A score: $<17$ is $28.3 \%$ each; (c) Moderate Anxiety with LAS: >10-20 and HAM-A score: 18-24 is 3.6\% each, (d) Severe Anxiety with LAS: $>20-30$ and HAM-A score: $25-30$ is $0.3 \%$; (e) Very Severe Anxiety with LAS: $>30$ and HAM-A score: $>30$ is $0 \%$ each. (iii) 71-80 years $(\mathrm{N}=178)$ that have: (a) LAS and HAM-A score less than the average score of 3.71 and 3.47 is $65.2 \%$ and $71.3 \%$ respectively, (b) Mild Anxiety with LAS: $>2.5-10$ and HAM-A score: $<17$ is $35.4 \%$ each, (c) Moderate Anxiety with LAS: $>10-20$ and HAM-A score: $18-24$ is 3.4\% each, (d) Severe Anxiety with LAS: $>20-30$ and HAM-A score: $25-30$ is $2.2 \%$ each, (e) Very Severe Anxiety with LAS: $>30$ and HAM-A score: $>30$ is $0.6 \%$ each.

(iv) 81-100 years $(\mathrm{N}=49)$ that have: (a) LAS and HAM-A score less than their respective average score of 2.2 and 1.08 are $69.4 \%$ and $89.8 \%$, (b) Mild Anxiety with LAS: $>2.5-10$ and HAM-A score: $<17$ is $16.3 \%$ each, (c) Moderate Anxiety with LAS: $>10-20$ and HAM-A score: 18-24 is 4.1\% each, (d) Severe Anxiety with LAS: $>20-30$ and HAM-A score: $25-30$ is $0 \%$ each, (e) Very Severe Anxiety with LAS: $>30$ and HAM-A score:>30 is $0 \%$ each. 


\section{B. In females:}

The observation is as follows,

(i) 51-60 years $(\mathrm{N}=587)$ that have: (a) LAS and HAM-A score less than their respective average scores of 2.72 and 1.80 are $74.1 \%$ and $77.5 \%$ respectively, (b) Mild Anxiety with LAS: $>2.5-10$ and HAM-A score: $<17$ is $30.1 \%$ each, (c) Moderate Anxiety with LAS: $>10-20$ and HAM-A score: $18-24$ is $1.9 \%$ each (d) Severe Anxiety with LAS: >20-30 and HAM-A score: $25-30$ is $0.3 \%$ each, (e) Very Severe Anxiety with LAS: $>30$ and HAM-A score: $>30$ is $0.2 \%$ each.

(ii) $61-70$ years $(\mathrm{N}=278)$ that have: (a) LAS and HAM-A score less than their respective average score of 3.45 and 3.15 are $69.1 \%$ and $72.7 \%$, (b) Mild Anxiety with LAS: $>2.5-10$ and HAM-A score: $<17$ is $33.8 \%$ each, (c) Moderate Anxiety with LAS: >10-20 and HAM-A score: 18-24 is 5\% each, (d) Severe Anxiety with LAS: $>20-30$ and HAM-A score: $25-30$ is 1\% each (e) Very Severe Anxiety with LAS: $>30$ and HAM-A score: $>30$ is $0 \%$ each. (iii) 71-80 years $(\mathrm{N}=89)$ that have: (a) LAS and HAM-A score less than the average score of 3.51 and 2.92 is 77.5\% each, (b) Mild Anxiety with LAS: $>2.5-10$ and HAM-A score: $<17$ is $25.8 \%$ each, (c) Moderate Anxiety with LAS: >10-20 and HAM-A score: $18-24$ is 2.2\% each, (d) Severe Anxiety with LAS: $>20-30$ and HAM-A score: 2530 is $2.2 \%$ each, (e) Very Severe Anxiety with LAS: $>30$ and HAM-A score: $>30$ is $1.1 \%$ each.

(iv) 81-100 years ( $\mathrm{N}=19)$ that have: (a) LAS and HAM-A score less than their respective average score of 3.10 and 3.17 are $73.7 \%$ and $78.9 \%$, (b) Mild Anxiety with LAS: $>2.5-10$ and HAM-A score: $<17$ is $21.1 \%$ each, (c) Moderate Anxiety with LAS: $>10-20$ and HAM-A score: 18-24 is 5.3\% each, (d) Severe Anxiety with LAS: $>20-30$ and HAM-A score: $25-30$ is $0 \%$ each, (e) Very Severe Anxiety with LAS: $>30$ and HAM-A score: $>30$ is $0 \%$ each. The percentage of the population in respective age groups for each gender is consistent for both the scores and in all the age groups, the population majorly lies in the grade of mild anxiety, then a moderate level of anxiety, while a very few of them suffering from severe anxiety.

Linear regressions and ANOVA tests. LAS has been plotted on HAM-A to see at what percentage the former can fit with that of the latter, by measuring the $\mathrm{R}^{2}$ and adjusted $\mathrm{R}^{2}$ values using regressions. ANOVA on the other hand, provides the $p$-values, if $<0.05$, the fitting model is found to be statistically significant. Fig. 3 shows the regression plots and the ANOVA results age and gender-wise.

In Fig. 3, the average $\mathrm{R}^{2}$ values for males and females are 0.93 and 0.95 , respectively, which corroborates the fact that LAS can explain 93\% and 95\% HAM-A self-score values correctly and are found as statistically significant (Cl: 95\%; p-values <0.05). Linear regression with ANOVA is a reliable estimate of the reliability and validity of any new method [20]. Thus, this is the first proof that LAS is reliable and valid, based on the results of the Linear regression and ANOVA.

Results of the Two-sample t-test (t-stat). A two-sample t-test in males (M) and females (F) is computed using the MS Excel Data Analysis package. Table 3shows the t-test results as (i) t-stat scores, (ii) t-critical one-tail (TCOT) and (iii) two-tail (TCTT) with their respective p-values (iv) pTCOT and (v) pTCTT), (vi) Pearson's correlation coefficient scores ( $r$ ) between LAS and HAM-A, their respective means (vii) mLAS and (viii) mHAMA), and variances (ix) vLAS and (x) vHAM-A according to age and gender. 
Table 3

Two Sample Paired t-Test results:

\begin{tabular}{|c|c|c|c|c|c|c|c|c|c|c|c|}
\hline Sex & Age & t-stat & $r$ & TСОТ & рTCOT & TCTT & рTCTT & mLAS & $\underset{A}{\operatorname{mHAM}}$ & vLAS & $\begin{array}{l}\text { vHAM- } \\
\text { A }\end{array}$ \\
\hline \multirow[t]{4}{*}{ M } & $\begin{array}{l}51- \\
60\end{array}$ & 19.57 & 0.98 & 1.65 & $\begin{array}{l}1.75 \mathrm{e}^{-} \\
72\end{array}$ & 1.96 & $\begin{array}{l}3.49 e^{-} \\
72\end{array}$ & 2.67 & 1.64 & 9.12 & 19.83 \\
\hline & $\begin{array}{l}61- \\
70\end{array}$ & 0.93 & 0.94 & 1.65 & 0.18 & 1.96 & 0.35 & 2.86 & 2.77 & 8.34 & 24.53 \\
\hline & $\begin{array}{l}71- \\
80\end{array}$ & 1.48 & 0.96 & 1.65 & 0.07 & 1.97 & 0.14 & 3.71 & 3.47 & 21.34 & 39.97 \\
\hline & $\begin{array}{l}81- \\
100\end{array}$ & 4.72 & 0.97 & 1.68 & $\begin{array}{l}1.04 \mathrm{e}^{-} \\
05\end{array}$ & 2.01 & 2.07 & 2.21 & 1.08 & 4.41 & 13.16 \\
\hline \multirow[t]{4}{*}{$\mathrm{F}$} & $\begin{array}{l}51- \\
60\end{array}$ & 11.38 & 0.96 & 1.65 & $\begin{array}{l}1.52 \mathrm{E}- \\
27\end{array}$ & 1.96 & $\begin{array}{l}3.03 E- \\
27\end{array}$ & 2.72 & 1.80 & 8.98 & 21.34 \\
\hline & $\begin{array}{l}61- \\
70\end{array}$ & 2.24 & 0.98 & 1.65 & 0.01 & 1.97 & 0.03 & 3.45 & 3.15 & 13.29 & 32.78 \\
\hline & $\begin{array}{l}71- \\
80\end{array}$ & 2.86 & 0.99 & 1.66 & 0 & 1.99 & 0.01 & 3.51 & 2.92 & 28.78 & 50.15 \\
\hline & $\begin{array}{l}81- \\
100\end{array}$ & -0.11 & 0.98 & 1.73 & 0.46 & 2.10 & 0.92 & 3.10 & 3.17 & 10.59 & 36.69 \\
\hline
\end{tabular}

Two samples (LAS and HAM-A) t-test, here, help us understand whether the respective mean anxiety scores of the two samples are equal or not (the two methods of measuring anxiety are the same or not), i.e. whether the null hypothesis needs to be accepted or rejected. From Table 3, it can be deduced that the mean scores of both the samples (LAS and HAM-A) are in the mild anxiety grade for all the respective age groups and gender, i.e. mLAS is between 2.5-10 and HAM-A is between 1-17 except for males in the age group of 81-100 years for which mLAS: 2.21 is a little lesser than and yet closer to the critical value of 2.5 and mHAM-A: 1.08 is closer to 1 indicating the predominance of closeness to mild anxiety. Since the scores are paired, there is a one-to-one correspondence between the two values of the samples.

The observation for both one-tail and two-tail t-stats is as follows:

\section{A. In males,}

(i) 51-60 years: $\operatorname{pTCOT}(\mathrm{T}<=\mathrm{t})$ one tail $(1.75 \mathrm{e}-72)$ and $\mathrm{pTCTT}(\mathrm{T}<=\mathrm{t})$ two tail $(3.49 \mathrm{e}-72)$ are less than 0.05 and give the probability that the absolute value of the t-Statistic (19.57) would be observed that is larger in absolute value than the critical t values (TCOT: 1.65; TCTT: 1.96). Hence, we reject the null hypothesis that there is no significant difference in the means of each sample (mLAS:2.67; mHAM-A: 1.64).

(ii) 61-70 years: $\mathrm{pTCOT}(\mathrm{T}<=\mathrm{t})$ one tail $(0.18)$ and $\mathrm{pTCTT}(\mathrm{T}<=\mathrm{t})$ two-tail $(0.35)$ are greater than 0.05 and give the probability that the absolute value of the t-Statistic (0.93) would be observed that is smaller in absolute value than the critical $t$ values (TCOT: 1.65; TCTT: 1.96). Hence, we accept the null hypothesis that there is no significant difference in the means of each sample (mLAS:2.86; mHAM-A: 2.77).

(iii) 71-80 years: $\mathrm{pTCOT}(\mathrm{T}<=\mathrm{t})$ one tail $(0.07)$ and $\mathrm{pTCTT}(\mathrm{T}<=\mathrm{t})$ two-tail $(0.14)$ are greater than 0.05 and give the probability that the absolute value of the t-Statistic (1.48) would be observed that is smaller in absolute 
value than the critical $t$ values (TCOT: $1.65 ;$ TCTT: 1.97). Hence, we accept the null hypothesis that there is no significant difference in the means of each sample (mLAS:3.71; mHAM-A: 3.47).

(iv) 81-100 years: $\mathrm{pTCOT}(\mathrm{T}<=\mathrm{t})$ one tail $(1.04 \mathrm{e}-05)$ and $\mathrm{PTCTT}(\mathrm{T}<=\mathrm{t})$ two-tail $(2.07)$ are lesser and greater than 0.05 respectively and give the probability that the absolute value of the t-Statistic $(4.72)$ would be observed that is larger or smaller in absolute value than the critical t values (TCOT: 1.68; TCTT: 2.01) respectively. Hence, we may reject or accept the null hypothesis that there is no significant difference in the means of each sample (mLAS: 2.86; mHAM-A: 2.77).

B. In females

(i) 51-60 years: $\mathrm{pTCOT}(\mathrm{T}<=\mathrm{t})$ one tail (1.52E-27) and pTCTT(T<= t) two-tail (3.03E-27) are less than 0.05 and give the probability that the absolute value of the t-Statistic (11.38) would be observed that is larger in absolute value than the critical $t$ values (TCOT: 1.65 ; TCTT: 1.96). Hence, we reject the null hypothesis that there is no significant difference in the means of each sample (mLAS:2.71; mHAM-A: 1.80 ).

(ii) 61-70 years: $\mathrm{pTCOT}(\mathrm{T}<=\mathrm{t})$ one tail $(0.01)$ and $\operatorname{pTCTT}(\mathrm{T}<=\mathrm{t})$ two-tail $(0.03)$ are less than 0.05 and give the probability that the absolute value of the t-Statistic (2.24) would be observed that is larger in absolute value than the critical t values (TCOT: 1.65; TCTT: 1.97). Hence, we reject the null hypothesis that there is no significant difference $(=0.3)$ in the means of each sample (mLAS:3.45; mHAM-A: 3.15$)$.

(iii) 71-80 years: $\operatorname{pTCOT}(T<=t)$ one tail $(0)$ and $\operatorname{PTCTT}(T<=t)$ two-tail $(0.01)$ are less than 0.05 and give the probability that the absolute value of the t-Statistic (2.86) would be observed that is larger in absolute value than the critical t values (TCOT: 1.66; TCTT: 1.99). Hence, we reject the null hypothesis that there is no significant difference $(=0.59)$ in the means of each sample (mLAS:3.51; mHAM-A: 2.92$)$.

(iv) 81-100 years: $\mathrm{pTCOT}(\mathrm{T}<=\mathrm{t})$ one tail $(0.46)$ and $\mathrm{pTCTT}(\mathrm{T}<=\mathrm{t})$ two-tail $(0.92)$ are greater than 0.05 and give the probability that the absolute value of the t-Statistic $(0.11)$ would be observed that is smaller in absolute value than the critical t values (TCOT: 1.73; TCTT: 2.10). Hence, we accept the null hypothesis that there is no significant difference $(=0.07)$ in the means of each sample (mLAS:3.10; mHAM-A: 3.17).

Larger and smallert-stat than the critical t-values indicate that the configuration of the two methods/samples are not the same and are the same respectively. The above overall results show that the difference between mLAS and mHAM-A may or not be significant as per the deductions from different age groups and gender. However, Table 3 indicates that vLAS is always significantly smaller than the vHAM-A, indicative of the fact that the grade ranges and, hence, the configuration for the two methodologies differ significantly, although the mean differences maintain consistency.

Moreover, for all the age groups for each gender, there is a strong positive correlation between LAS and HAM-A indicated by the r-value greater than 0.9 in each case (Table 3). This is the second proof though LAS and HAMA are not similar instruments based on their modalities and scales, yet, LAS is a reliable and valid instrument in monitoring anxiety. It may be noted here that the two independent testing methodologies used in the same subjects give similar results in the grade of anxiety, however, the value ranges (or the configuration) are different for both.

Bland-Altman reliability assessment tests. Age-group- and gender-wise Bland-Altman plots are drawn along with all females, all males, and the total dataset to check the degree of agreement between LAS and HAM-A by gauging the degree of difference for their respective mean values. By plotting the difference against the mean value, limits of agreement ( $L O A)$ are calculated in which $95 \%$ of data points should lie within Upper LOA and 
Lower LOA (which are \pm 1.96 standard deviation of the bias, the mean of difference). In section 3.4, a strong positive correlation has already been established between LAS and HAM-A ( $>0.90$ for all entries). However, this does not necessarily denote agreement. Agreement exists between two methods only if the data points lie along the line of equality. If the two methodologies have different scales (or configurations), the correlation may not get affected, but the agreement does. Confidence interval $(\mathrm{Cl})$ is calculated simultaneously to denote the probability that the data points will fall between the LOA values around the mean.

The observation is as follows:

(i) In males, $\mathrm{Cl}$ of $10.29 \%$ (age group $51-60$ years), $18.87 \%$ (age group $61-70$ years), $45.71 \%$ (age group $71-80$ years), $46.65 \%$ (age group 81-100 years), and 9.37\% (for all males) denote the chances of data points exist within the Limit of agreement (LOA). This is indicative of the least agreement depicting the difference of scales in the two instruments (LAS and HAM-A).

(ii) In females, $\mathrm{Cl}$ of $15.69 \%$ (age group 51-60 years), $26.72 \%$ (age group 61-70 years), 40.89\% (age group 7180 years), and $12.95 \%$ (for all females) denote the chances of data points exist within LOA. This is indicative of the least agreement depicting the difference of scales in the two methodologies. $\mathrm{Cl}$ of $131.13 \%$ (age group 81-100 years) shows strong agreement between the two instruments, but this result may be attributed to the limited population (=19) available in the age group.

(iii) The overall agreement (for all the subjects taken together) of $12.95 \%$ is shown due to different scales of measurement.

Hence, it may be concluded that there is a strong positive correlation between LAS and HAM-A. Although the methods have different scales of measurement, the grade (anxiety levels) for their corresponding scale range matches accurately.

Computation of classification error of LAS on HAM-A. Comparing the classification ability of LAS (the new instrument) on HAM-A self-score, which is the well-acclaimed instrument is another important step to assess its reliability in class-prediction, based on the computed number of True positive (TP), True negative (TN), False positive (FP), and the False-negative (FN) cases. Then by using these values, Sensitivity (Sn), Specificity $(S p)$, Precision (P), Accuracy (A), Fscore (F), and Youden's index or j-statistics (j) is calculated [10]. Table 4 showcases the computed values.

It is important to note that the class 'positivity' increases with the grades, which means that in case LAS classifies one case as 'mild', which is 'moderate' in HAM-A, the interpretation is that, LAS is diagnosing it as an FN case. The difference in the grading is obvious as LAS and HAM-A grades have different ranges; however, its qualitative definitions as 'mild', 'moderate', and 'severe' are mapped based on the above criteria. 
Table 4

Classification matrix of LAS compared to HAM-A

\begin{tabular}{|c|c|c|c|c|c|c|c|c|c|c|}
\hline \multicolumn{11}{|c|}{ Total 2810 (M: 1837; F: 973) } \\
\hline & TP & FP & $\mathrm{TN}$ & FN & Sn & Sp & $\mathbf{P}$ & A & $\mathbf{F}$ & $\mathbf{j}$ \\
\hline $\begin{array}{l}51-60 \text { years } \\
(M=977, F=587)\end{array}$ & $\begin{array}{l}812 \\
498\end{array}$ & $\begin{array}{l}60 \\
30\end{array}$ & $\begin{array}{l}82 \\
59\end{array}$ & $\begin{array}{l}23, \\
0\end{array}$ & $\begin{array}{l}0.97 \\
1.0\end{array}$ & $\begin{array}{l}0.58 \\
0.66\end{array}$ & $\begin{array}{l}0.93 \\
0.94\end{array}$ & $\begin{array}{l}0.92 \\
0.95\end{array}$ & $\begin{array}{l}0.95 \\
0.97\end{array}$ & $\begin{array}{l}0.55 \\
0.66\end{array}$ \\
\hline $\begin{array}{l}\text { 61-70 years } \\
(\mathrm{M}=633), \mathrm{F}=278)\end{array}$ & $\begin{array}{l}450 \\
120\end{array}$ & $\begin{array}{l}66 \\
35\end{array}$ & $\begin{array}{l}94, \\
93\end{array}$ & $\begin{array}{l}23 \\
30\end{array}$ & $\begin{array}{l}0.95 \\
0.8\end{array}$ & $\begin{array}{l}0.59 \\
0.73\end{array}$ & $\begin{array}{l}0.87 \\
0.77\end{array}$ & $\begin{array}{l}0.86 \\
0.77\end{array}$ & $\begin{array}{l}0.91 \\
0.79\end{array}$ & $\begin{array}{l}0.54 \\
0.53\end{array}$ \\
\hline $\begin{array}{l}71-80 \text { years } \\
(\mathrm{M}=178), \mathrm{F}=89)\end{array}$ & $\begin{array}{l}117 \\
50\end{array}$ & $\begin{array}{l}20 \\
19\end{array}$ & $\begin{array}{l}41 \\
35\end{array}$ & $\begin{array}{l}0 \\
5\end{array}$ & $\begin{array}{l}1.0 \\
0.91\end{array}$ & $\begin{array}{l}0.67 \\
0.65\end{array}$ & $\begin{array}{l}0.85 \\
0.72\end{array}$ & $\begin{array}{l}0.89 \\
0.78\end{array}$ & $\begin{array}{l}0.92, \\
0.81\end{array}$ & $\begin{array}{l}0.67 \\
0.56\end{array}$ \\
\hline $\begin{array}{l}81-100 \text { years } \\
(\mathrm{M}=49), \mathrm{F}=19)\end{array}$ & $\begin{array}{l}30 \\
10\end{array}$ & 2 & $\begin{array}{l}15 \\
8\end{array}$ & $\begin{array}{l}2, \\
0\end{array}$ & $\begin{array}{l}0.94 \\
1.0\end{array}$ & $\begin{array}{l}0.88 \\
0.89\end{array}$ & $\begin{array}{l}0.94 \\
0.91\end{array}$ & $\begin{array}{l}0.92, \\
0.95\end{array}$ & $\begin{array}{l}0.94 \\
0.95\end{array}$ & $\begin{array}{l}0.82 \\
0.89\end{array}$ \\
\hline AVERAGE & & & & & $\begin{array}{l}0.97 \\
0.93\end{array}$ & $\begin{array}{l}0.68 \\
0.73\end{array}$ & $\begin{array}{l}0.89 \\
0.84\end{array}$ & $\begin{array}{l}0.89 \\
0.86\end{array}$ & $\begin{array}{l}0.93 \\
0.88\end{array}$ & $\begin{array}{l}0.65 \\
0.66\end{array}$ \\
\hline
\end{tabular}

\section{Explanation of Table 4:}

Sensitivity of 0.97 and 0.93 for male and female subjects indicate that LAS can correctly detect by $97 \%$ and $93 \%$ the positively labeled or graded anxiety levels out of the total subjects who have anxiety in reality.

Specificity of 0.68 and 0.73 in males and females support the fact that LAS can correctly detect by $68 \%$ and $73 \%$ of the negatively graded anxiety levels, which is nothing but the normal population out of the total healthy subjects. The precision of 0.89 and 0.84 for male and female populations indicates that $89 \%$ and $84 \%$ of the population who are labeled in the respective grades have anxiety levels corresponding to that particular grade. The accuracy of $89 \%$ and $86 \%$ for males and females, respectively establishes how correctly LAS can grade the anxiety levels out of all the subjects. F-score of $93 \%$ and $88 \%$ for males and females measure that the grading of anxiety is well-balanced between precision and sensitivity of the classification matrix. The jstatistics (Youden's index) of $65 \%$ and $66 \%$ in males and females state the fact that LAS can balance sensitivity, i.e., detecting anxiety levels, and specificity, i.e., detecting the healthy condition. Its value of over $50 \%$ is a good empirical benchmark for diagnostic purposes [21].

\section{Conclusions}

The paper concludes that,

- Lyfas is a robust smartphone-based biomarker instrument, i.e., it is not hypersensitive to the time of the test.

- It has high accuracy (94.7\%).

- A high Youden's index (over 65\% on average) corroborates the fact that Lyfas is an industry-standard instrument for monitoring anxiety disorder.

- It is positively correlated ( $r=97 \%)$ with HAM-A self scores. 
- Lyfas measures anxiety scores with the help of an important CVb (using SDPPG): SD1/SD2, which comprises HR, RMSSD, pNN50, SDNN, LF, HF, and HRV in its calculation and hence is a real-time, realistic, and holistic biomarker to gauge the condition of baroreflex working. Whereas HAM-A gauges the anxiety levels using the symptoms-related questions, LAS measures the psychological, physiological, and pathological components, that is the root cause of a clinical condition giving a more holistic scenario using the simple method of capturing the CVbs.

- Taken together, LAS, by using the CVb for understanding the root causes, extends the current existing efforts to measure anxiety using smartphone sensors, HAM-A, or a combination of HAM-A and virtual realities that mostly rely on detecting the nuanced behavioral symptoms of anxiety.

- The current study has only classified and graded the overall anxiety levels in a particular group of individuals, i.e., middle-aged and elderly population. Future work can present a deeper application and analysis of Lyfas $\mathrm{CVb}$ in detecting the different types of anxiety disorders like generalized anxiety, obsessive-compulsive, panic, post-traumatic stress, and social anxiety disorders across all age groups.

\section{Declarations}

\section{Data Availability Statement}

The dataset generated during and/or analyzed during the current study is not publicly available due to patient privacy issues.

\section{Acknowledgments:}

TIDE 2.0 Program, DERBI Foundation, The Ministry of Electronics and Information Technologies, Govt. of Karnataka, India. Certificate number: IN-KA45186921153022T, Dated: $13^{\text {th }}$ July 2021.

We would also like to thank Yogesh Kumar Mangal for data analytics and visualization.

\section{Author contributions}

The concept of the study, its flow and structure, and paper writing have been performed by S.C. R.D. has developed the Lyfas application, designed the methodology, conducted the study, and reviewed the paper. S.G. has conducted all statistical analyses, compiled the results, mined the data into meaningful information, and reviewed the paper.

\section{Competing Interest:}

The authors declare that there is no personal or organizational conflict of interest with this work.

\section{Additional Information:}

Correspondence and request for materials should be addressed to S.C.

\section{References}


1. Muskin, P.R. What Are Anxiety Disorders? American Psychiatric Association

https://www.psychiatry.org/patients-families/anxiety-disorders/what-are-anxiety-disorders (2021)

2. $\mathrm{Yu}, \mathrm{Y}$. Pathogenesis of anxiety disorders. The Calgary Guide to Understand Disease https://calgaryguide.ucalgary.ca/pathogenesis-of-anxiety-disorders/ (2013)

3. Olson C.M. Familial Factors in the Development of Social Anxiety Disorder. J Psychosoc Nurs Ment Health Serv. 59(7), 23-34 (2021).

4. Chattopadhyay, S. \& Shinha, P. Understanding factors impacting covid vaccination in India: A preliminary report. QJMHS. 1(3), 18-31 (2021).

5. Vahia, I.V., Jeste D.V., \& Reynolds, C.F. Older Adults and the Mental Health Effects of COVID-19. JAMA. 324(22), 2253-2254 (2020).

6. Sandín, B. et al. Effects of Coronavirus Fears on Anxiety and Depressive Disorder Symptoms in Clinical and Subclinical Adolescents: The Role of Negative Affect, Intolerance of Uncertainty, and Emotion Regulation Strategies. Front. Psychol. 12, 716528 ( 2021).

7. Anxiety Test. Mental Health America https://screening.mhanational.org/screening-tools/anxiety/.

8. Self-Screening. Anxiety \& Depression Association of America https://adaa.org/find-help/treatmenthelp/self-screening.

9. $\quad$ Cheriyedath, S. Photoplethysmography (PPG). News Medical Life Sciences https://www.newsmedical.net/health/Photoplethysmography-(PPG).aspx.

10. Chattopadhyay, S. \& Das, R. Comparing Heart Rate Variability with Polar H10 Sensor and Pulse Rate Variability with LYFAS: A Novel Study. J Biomed Eng. 9(1), 1-9 (2021).

11. Fleming, A. The stress test: What heart rate variability can tell you about your mental health. Science Focus https://www.sciencefocus.com/the-human-body/the-stress-test-what-heart-rate-variabilitycan-tell-you-about-your-mental-health/ (2020).

12. Lyfas https://www.lyfas.com/

13. Das, R. \& Chattopadhyay, S. Towards Cardiac Risk Monitoring of Duchene Muscular Dystrophy using Lyfas. J. Nanotech. Diagn. Treat. 7, 25-32 (2021).

14. Chattopadhyay, S. \& Das, R. Lyfas, A Smartphone-based Subclinical Depression Tracker. Int J Psychiatr Res. Accepted in press (2021).

15. Deepa H.S., \& Das, R. Evaluation of non-invasive smartphone based digital biomarker tool lyfas in detecting sleep deficiency and its effects: a retrospective observational study. Indian J. Appl. Res. 11(1), 46-47 (2021).

16. Shaffer, F. \& Ginsberg, J.P. An Overview of Heart Rate Variability Metrics and Norms. Front. Public Health. 5, 258 (2017).

17. Swenne, C.A. Baroreflex sensitivity: mechanisms and measurement. Neth Heart J. 21(2), 58-60 (2013).

18. Shaffer, F., McCraty, R. \& Zerr, C.L. A healthy heart is not a metronome: an integrative review of the heart's anatomy and heart rate variability. Front. Psychol. 5, 1040 (2014).

19. Popov, T.A., et al. Medical devices in allergy practice. World Allergy Organ. J. 13(10), 100466 (2020).

20. Horn, A. \& Lee, G. The Reliability and Validity of Using Regression Residuals to Measure Institutional Effectiveness in Promoting Degree Completion. Res High Educ. 57(4), 469-496 (2016).

21. Ghoneim, S. towards data science https://towardsdatascience.com/accuracy-recall-precision-f- 
score-specificity-which-to-optimize-on-867d3f11124 (2019).

22. Heidel, E. Diagnosis. https://www.scalestatistics.com/youden-index.html.

\section{Figures}
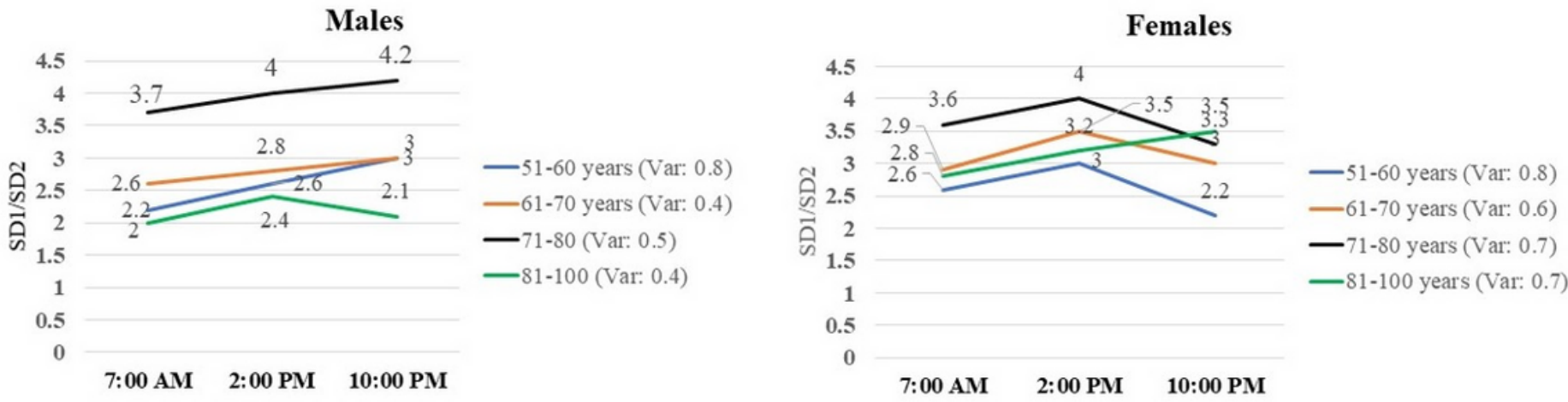

\section{Figure 1}

Results of the Lyfas hypersensitivity test.
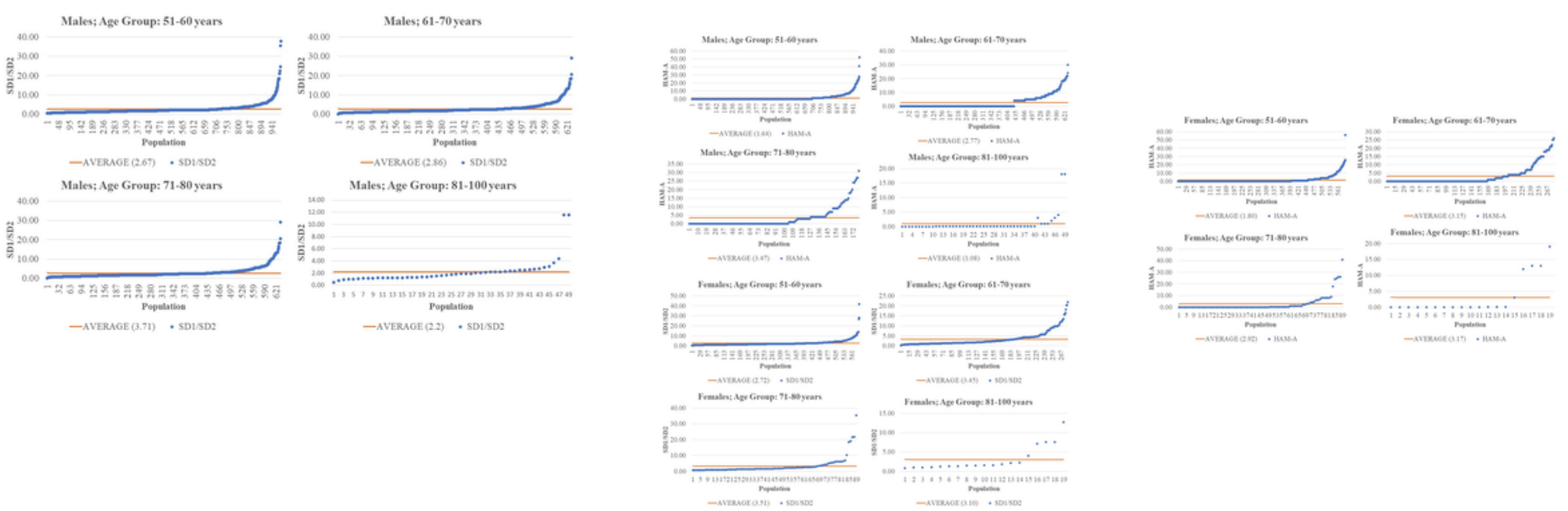

Figure 2

LAS and HAM-A distributions. 
Male; Age Group: 51-60 years

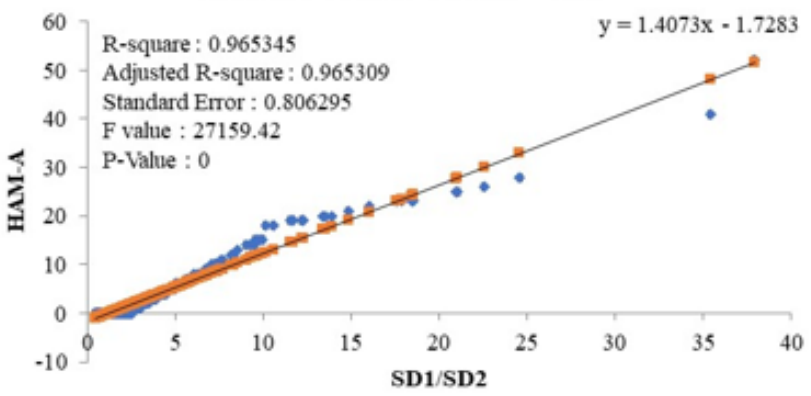

\section{Male; Age Group: 71-80 years}

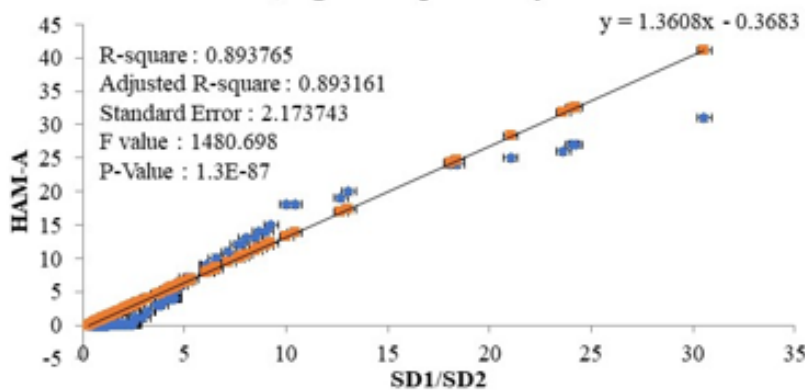

Female; Age Group: 51-60 years

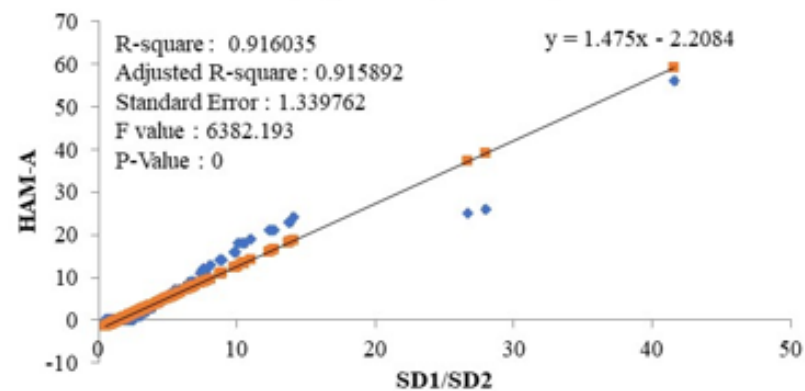

Female; Age Group: 71-80 years

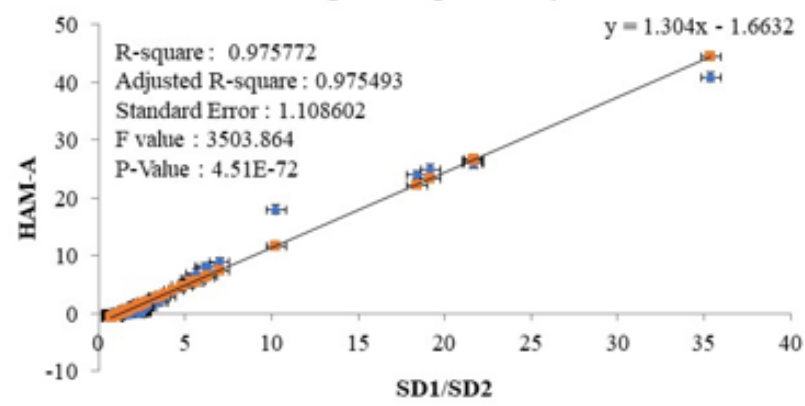

Male; Age Group: 61-70 years

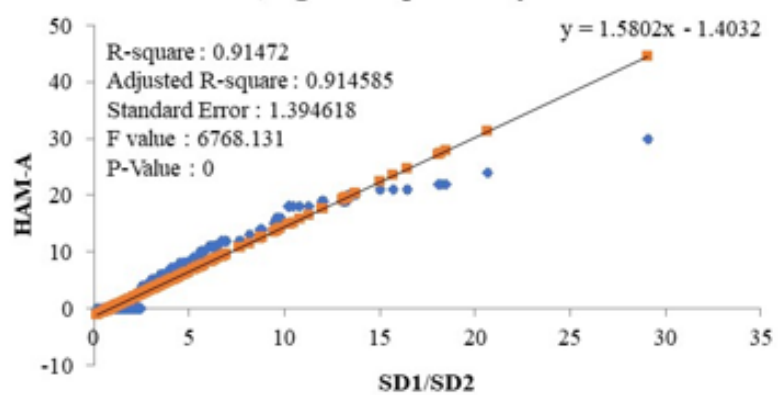

Male; Age Group: 81-100 years

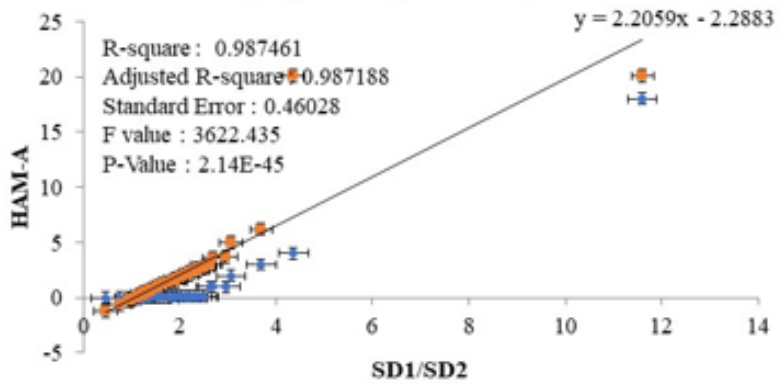

Female; Age Group: 61-70 years

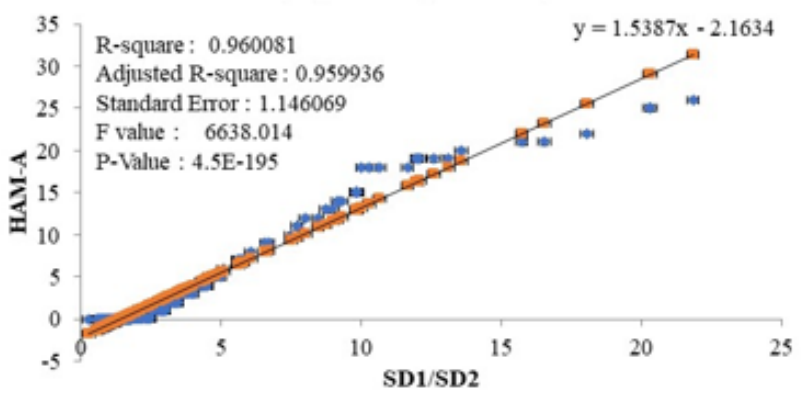

Female; Age Group; 81-100 years

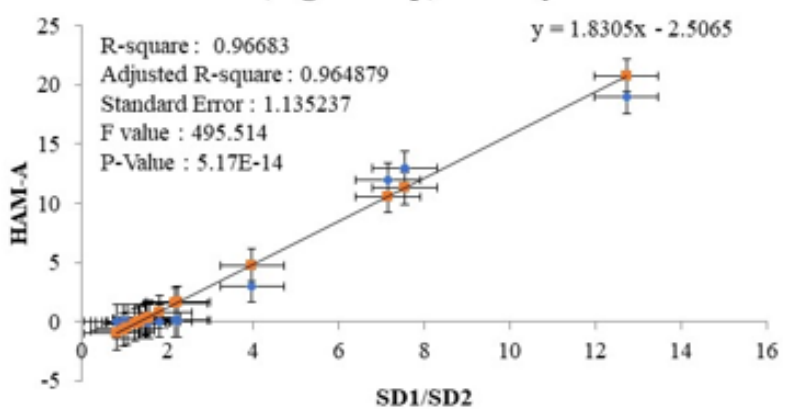

Figure 3

Regressions and ANOVA results. 

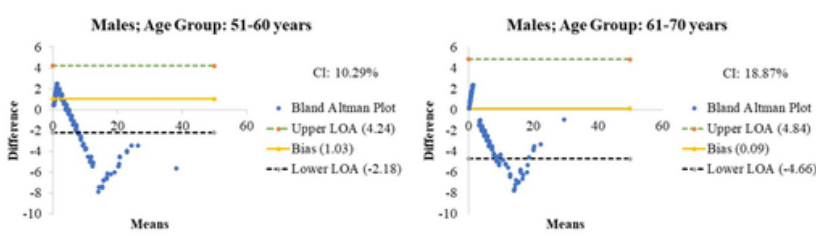

Males; Age Group: 71-80 year
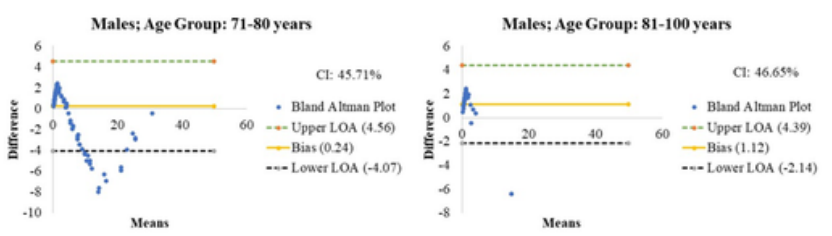

Females; Age Group: 51-60 years

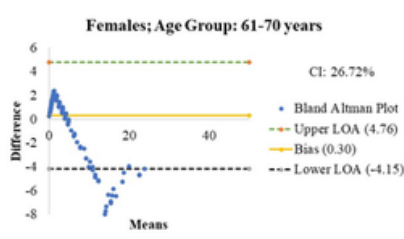

vales; Age Group: 71-80 years

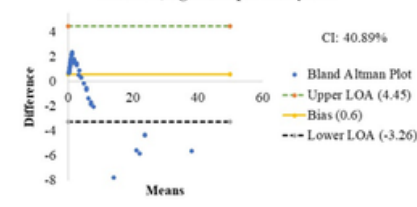

Females; Age Group: 81-100 years

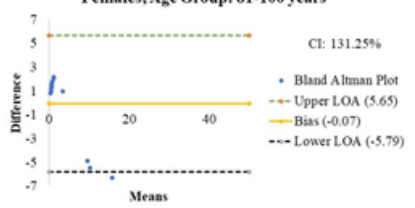

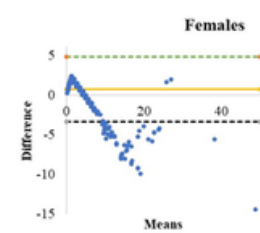
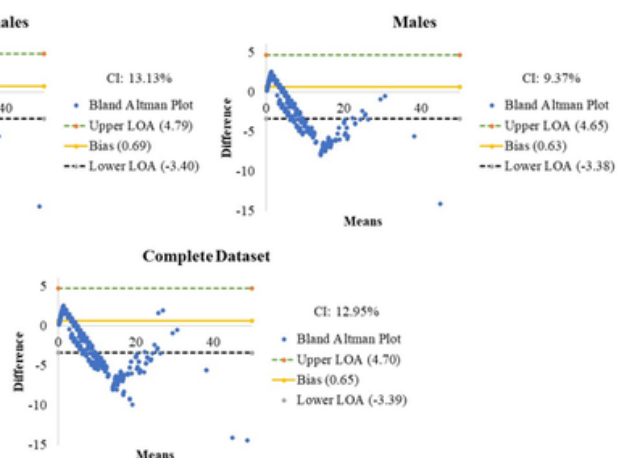

Figure 4

Bland Altman plots. 